\title{
ICT for Independent Living - Business model insights
}

\author{
Barry, J.; Luherne, M; van Glabbeek, G. \\ ${ }^{1}$ Aaliance 2 - European Next Generation Ambient Assisted Living Innovation Alliance \\ ${ }^{2}$ European Union Framework Project
}




\section{Independent living is a mega-trend}

The market for Ambient Assisted Living is still in its infancy. In 2012 most countries are facing a radical population shift that will tax the current status quo. In addition to the most populous generation (so called Baby Boom generation 1945-1964) reaching retirement age, the resources used to support the so called Silent Generation (1925-1945) cannot scale to support the Baby Boom generation because the population is constricting and the economic outlook is much more conservative than in the 1980s and 1990s (GDP growth of $1.8 \%$ co mpared to 2.8 in the last 20 years). Mapping the Care social structure to identify the key participants will serve as a guide that will be used to evaluate business models that may or may not be addressed in the market today.

A key measure of a countries' ability to support any population is expressed through dependency ratios. The aged dependency ratio (figure one) is the number of people over 65 years of age divided by the number of people 15-64 years old. This does not address the ability of younger population's ability to support or the aged population's need for support.

In the following figures demonstrate that the dependency ratio has increased significantly in the last 22 years and (in the second figure) will continue at a similar rate through 2050 .

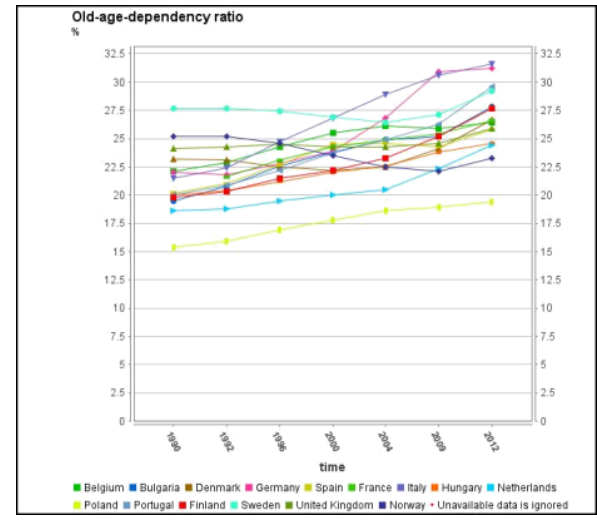

Fig. 1: Historical aged dependency trend for selected European counties 1990-2012

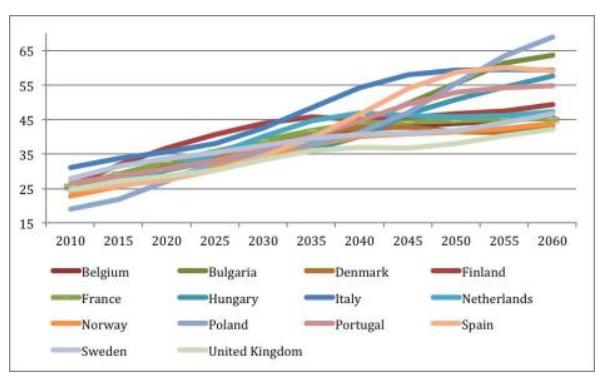

Fig. 2: Projected aged dependency trend for selected European countries 2010-2060

Based on the aged dependency ratio projections, counties will have to either retrain a substantial part of their labour force to support the aged population or use technology to make caring for the aged a less labour intensive activity

\section{EU action to address so- cietal change}

The social and economic challenges in Europe affecting the increasing longer lives in society and the potential offered by ICT for meeting these challenges have received increasing policy attention. The European Commission adopted an Action Plan on Information and Communication Technologies for Ageing in the framew ork of its i2010 Initiative (European Commission, 2007). The plan's goals are to raise aw areness, overcome technical and regulatory barriers, accelerate take-up and boost research and innovation. This has shaped EU's frameworks 6 and 7 and includes the Aaliance2 project. The Ac-ton plan emphasizes that ICT holds considerable potential for more efficient management and delivery of health and social care, as w ell as increasing opportunities for community care, self care and service innovation. Over the years the Action plan has been effective in leading significant technology development and in creating many pilots to prove the ability and effectiveness of solutions, but the markets are developing at a pace slower than what $w$ as anticipated.

\section{What is the AAL market?}

The AAL market in 2013 is best described as the intersection of three differ- 


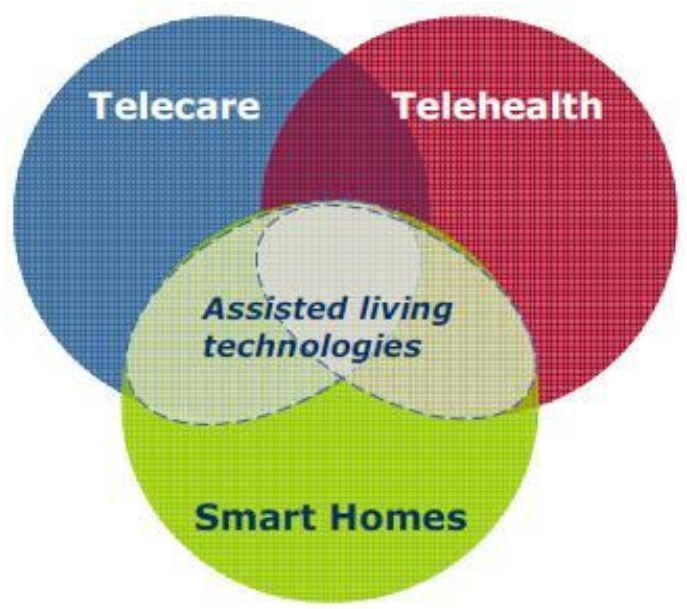

Fig. 3 Diagram of as sistive technology markets and their relationship to each other.

ent markets: Telecare, Telehealth and Smart Homes/home automation. Of these three markets telecare is the most established with services available across Europe. Telecare services in Europe are typically government funded or subsidised.

Telehealth is smaller than telecare, but with potential for fast growth due to the clear connection to the broad health services market. To date in Europe the UK has made the most progress in scale deployment of telehealth by changing the care pathways used in the NHS and locally deploying telehealth. Spain and Denmark have both structurally included telehealth in their care pathway design in 2012 and both markets are expected to show significant telehealth growth in 2013. Outside of Europe the US Veterans Administration has established itself as the largest user of telehealth with over 65,000 patients (US VA February 2012). Smart Homes and home automation is also a developing market. For a decade the home automation market has been expecting a surge in market growth, but the surge has not yet begun. Mass deployment of smart electricity meters along with increasing energy prices may be the catalyst the market has been looking for. Several electricity-supplying companies are offering services to monitor evaluate and suggest how to use electricity more efficiently. This is creating a financial incentive for homeowners to consider automated systems similar to solutions found in commercial buildings like motion sensors to control lighting.

Figure 3 identifies Ambient Assisted Living as the overlap of telecare, telehealth and smart homes. This definition is clear in the Venn diagram, but is not so clear in practical use. Few solutions include components from all three domains and most focus in the overlapping space of any two. This figure is widely used to explain the relationship between telecare, telehealth and smart homes and is the reference point for defining the AAL market.

\section{Business model insights}

\subsection{AAL at work}

As the population ages the is sue of supporting people at work will increase. This topic has been discussed in past studies, but is likely to increase in importance. Since 2010 Spain, Austria and Slovakia have increased the retirement age. The UK and Germany have enacted gradual increase spanning to 2029 . These policy changes are one factor influencing 
how long people work, but it is not the only indicator. The long-term economic growth projections for Europe predict slower growth in the future that has been experienced in the previous decades (Economic Outlook, 2012). The projected slower economic growth, increases in the retirement age and larger ageing population indicate that more people will be working to an older age in the future.

\subsection{Definition of AAL}

ICT and Ageing - European Study on Users, Markets and Technologies defined AAL as the intersection of Telecare, Telehealth and Smart Homes. Taking the overlap of the three value domains is unnecessarily restrictive and the AAL market is better described as the evolution of Telecare, Telehealth or Smart Homes where solutions actively support people to address challenges in living. Using the broader definition, where the focus is in the change from passive solutions to active solutions, will not exclude the narrow definition and will include innovations from each of the three component do-mains. Changing the definition also in-tends to focus on the interaction of infor-mation between and within the domains rather than within any one solution.

\subsection{Understanding the Ageing population}

Age is a convenient way to segment larger groups of people to draw broad conclusions. As the population of people over 65 increases; so will the complexity of their needs, desires and dreams. The tra- ditional view of market research is to either exclude people over 65 in market research or to create one age category that is "aged 65 and older". When creating new goods or services for people 65 years or older, traditional market research is limited in value due to this tradition. So ciety's understanding of ageing issue is changing as the population of older people increases. Developing products and services based on a stereotype view of "the elderly" is unlikely to lead to effective solutions. Several options are available to develop a better understanding of people's needs as they age.

- Improved market research that specifically targets people over 65

- Ethnographic studies of how older people are living

- Involving representative target users in design and development of services

- Focusing on challenges in living across age groups as many is-sues that affect people as they age also affect younger people as well

Older people are no more homogeneous than younger people; they have similar needs and dreams. The AAL market effectiveness depends on the end-user understanding how the goods or services benefit them, their family, their carers and the larger society. Without the user understanding the benefits it is unlikely that AAL will develop as a market.

\subsection{Government leadership}

AAL is a strategic initiative to address the 
societal changes in the next decades. The $\mathrm{EU}$ is investing in to prove the value of AAL goods and services but it will be the member counties and markets that will make it commercially viable. Leading locations like the Basque state and Denmark mentioned in this document and others like Northern Ireland, Finland and Estonia to name a few; are reorganizing how care and health are managed. They are managing care and health from the perspective of the users and in the process removing barriers between their care and health provisioning, monitoring and management systems.

Due to the existing government subsidies for care and health, the likelihood of a purely private AAL market developing in Europe is low. In Europe, people expect the government to play a role in defining services and subsidy levels. Companies entering a market where the government policy is not clear, run the risk that indi-viduals will delay purchasing until there is a clear policy.

Without active government participation in defining AAL business solutions the market will continue to develop, as it has to date - either as an evolution of tel-ecare, telehealth or smart homes. These approaches are likely to resulted in a more fragmented market place where care, health and housing are dealt with in isolation rather than holistically.

\section{How can ICAICTBM 2013 members get involved?}

The Aaliance2 EU project has two main goals: update the technology roadmap for AAL and expand the community of organisations participating in the AAL market.

The roadmap is a continuation of three European Union projects Aaliance, BRAID and CAPSIL. An updated draft roadmap was released in April 2013. It will remain draft for roughly six months to allow for review through comments, workshops and presentations.

The Aaliance 2 community is also a continuation of the CAPSIL and Aaliance projects. ICAITBM members can join the Aalinace community and receive updates on AAL events across the globe. In addition to the roadmap the Aaliance community includes reports on market status, standards is sues and industry conferences.

As part of the standards work, Aaliance has compiled a wiki of relevant standards that relate to AAL and will be generating a standards overview document to complement the wiki database.

\section{Join Aaliance 2 \\ www.aaliance.eu}

